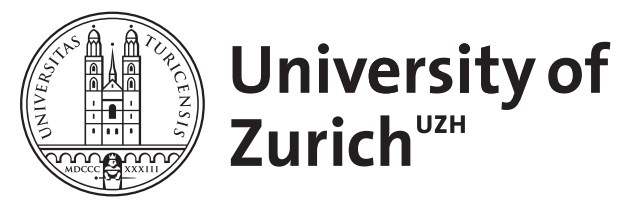

\title{
Ultrasonography of the abomasum in 30 Saanen goats
}

\author{
Braun, Ueli ; Jacquat, D
}

\begin{abstract}
This report describes the findings of ultrasonographic examination of the abomasum in 30 goats. A 5.0 MHz linear transducer was used to scan the left and right paramedian regions, the linea alba and the right abdominal wall of standing goats. The abomasum appeared as a heterogeneous, moderately echogenic structure with echogenic stippling. The abomasum could be seen from the linea alba in all the goats. The abomasal folds were easily identified in 19 goats and appeared as prominent echogenic bands. The cranial visible limit of the abomasum was $-0.3[2.34] \mathrm{cm}$ from the xyphoid, and the caudal limit was 10.3 [3.08] $\mathrm{cm}$ caudal to the xyphoid. The visible length of the abomasum was $10.7[1.96] \mathrm{cm}$ and the maximum width $30.2[7.43] \mathrm{cm}$. The height of the abomasum was $6.7[1.79] \mathrm{cm}$.
\end{abstract}

DOI: https://doi.org/10.1016/j.rvsc.2011.03.013

Posted at the Zurich Open Repository and Archive, University of Zurich

ZORA URL: https://doi.org/10.5167/uzh-58444

Journal Article

Accepted Version

Originally published at:

Braun, Ueli; Jacquat, D (2012). Ultrasonography of the abomasum in 30 Saanen goats. Research in Veterinary Science, 92(2):295-298.

DOI: https://doi.org/10.1016/j.rvsc.2011.03.013 
Revised Version 2: Inserted words are marked in red

2

3 Short Communication: Ultrasonography of the abomasum in 30 Saanen goats

4

5

6

7

U. Braun*, D. Jacquat

8

9

10

11

12

Department of Farm Animals, University of Zurich, Winterthurerstrasse 260, CH-8057 Zurich,

13

Switzerland

14

15

16

17

18

19

20

21

22

23

24

25 
26 * Corresponding author: Tel.: +41-1-6358241; fax: +41-1-6358904

27 E-mail address: ubraun@vetclinics.uzh.ch (U. Braun)

28 


0

\section{ABSTRACT}

This report describes the findings of ultrasonographic examination of the abomasum in 30 goats. A 5.0 $\mathrm{MHz}$ linear transducer was used to scan the left and right paramedian regions, the linea alba and the right abdominal wall of standing goats. The abomasum appeared as a heterogeneous, moderately echogenic structure with echogenic stippling. The abomasum could be seen from the linea alba in all the goats. The abomasal folds were easily identified in 19 goats and appeared as prominent echogenic bands. The cranial visible limit of the abomasum was $-0.3[2.34] \mathrm{cm}$ from the xyphoid, and the caudal limit was 10.3 [3.08] cm caudal to the xyphoid. The visible length of the abomasum was 10.7 [1.96] $\mathrm{cm}$ and the maximum width $30.2[7.43] \mathrm{cm}$. The height of the abomasum was $6.7[1.79] \mathrm{cm}$.

Keywords: Goat; Abomasum; Ultrasonography

The abomasum in goats is situated mainly in the cranioventral region of the abdomen

(Cegarra and Lewis, 1977). Compared with cattle, the caprine abomasum is proportionally larger and has a capacity of 2.1 to 4.0 litres in adults (Smith and Sherman, 2009). Abomasal diseases may affect young as well as older goats. Pyloric obstruction by phytobezoars has been described in adult goats (Bath, 1978; Bath and Berg, 1979). Abomasal emptying defects, which are part of functional pyloric stenosis in cattle, have also been reported in goats (Edwards and Nevel, 2008). Abomasal impaction is seen mainly in goats ingesting feeds high in indigestible fibre and not drinking adequate amounts of water (Linklater and Smith, 1993; Matthews, 2009b). Abomasal impaction attributable to metal particles has also been described (Purohit et al., 1986). Haemonchus contortus and Teladorsagia circumcincta are two important endoparasites that affect the abomasum (Matthews, 2009a). Severe haemonchosis results in oedema and congestion of the abomasal mucosa and marked enlargement of the abomasal lymph nodes (Pérez et al., 2001). Retrograde congestion of the abomasum attributable to 
ileus of the small intestine has been described in cattle (Braun, 2003) and has been reported in a goat with duodenal obstruction caused by a phytobezoar (Sherman, 1981). In contrast to cattle, left and right displacement of the abomasum is extremely rare in goats (Smith and Sherman, 2009). There is only one case report in the literature (West et al., 1983). Thorough evaluation of the normal abomasum cannot be achieved by physical examination alone. Since ultrasonography has been used to evaluate the abomasum in healthy cows (Braun et al., 1997a) and in cows with left (Braun et al., 1997b) and right abomasal displacement (Braun and Feller, 2008) as well in calves to study the position, capacity and rate of emptying of the abomasum (Wittek et al., 2005), it was the goal of the present study was to describe the position, size and appearance of the abomasum in 30 healthy Saanen goats. The information would provide reference values when evaluating goats with abomasal disease. were used. They were fed hay ad libitum and not fasted before the ultrasonographic examination. The study protocol was approved by the Animal Care Committee of the Canton of Zurich, Switzerland. Ultrasonographic examinations were carried out in standing, non-sedated animals using a 5.0 $\mathrm{MHz}$ linear or convex transducer with a penetration depth of $10 \mathrm{~cm}$, as described recently (Jacquat, 2010). The abomasum was examined from the right and left paramedian regions, the linea alba and the right abdominal wall. The location of the abomasum and appearance of its wall, folds and contents were assessed. Neighbouring organs were identified. The visible size of the abomasum was determined using the method described for cattle (Braun et al., 1997a). Identification of the cranial and caudal limits of the abomasum were evaluated from the linea alba. The distance between the cranial and caudal abomasal limits and the caudal end of the xyphoid was measured with a measuring tape (Fig. 1). The distance between the two limits was considered the visible length of the abomasum in the region of the linea alba (Fig. 2). The width of the abomasum was determined at the point where the maximum 
transverse dimension of the abomasum was seen. A measuring tape was used to measure the distance from the linea alba to the maximum right and left abomasal limits. The vertical dimension of the abomasum (abomasal height) was determined electronically from the linea alba at the point where the maximum vertical dimension of the abomasum was seen (Fig. 2).

After examination, the goats were slaughtered $(n=14)$ or euthanized $(n=16)$. A macroscopic postmortem examination of the abomasum was carried out in the slaughtered goats. The euthanased goats, which were also used in other studies (Becker-Birck, 2009; Steininger, 2009; Irmer, 2010), were frozen and cut into 1.0 to $1.5 \mathrm{~cm}$-thick transverse sections. On each transverse section the abomasum was examined.

The abomasum appeared as a heterogeneous, moderately echogenic structure with echogenic stippling, similar to the description reported in cattle (Braun et al., 1997a; Braun, 2003) (Fig. 3). The abomasum could always be differentiated from the neighbouring organs. It could be seen from the linea alba in all the goats and was directly adjacent to the abdominal wall in this region. The abomasum was visible from the right or left paramedian region in all the goats but it was seen from both sides in only 29. The abomasal wall could not be seen in any of the goats. The abomasal folds were easily recognised in 19 goats and appeared as prominent echogenic bands (Fig. 4). However, in eight goats they were difficult to identify and in two, they could not be seen at all. The abomasal folds were seen particularly well during reticular contractions. The pylorus could be clearly identified in only one goat (Fig. 5). It was round with a hypoechogenic lumen and an echogenic torus pyloricus and pyloric folds. The torus pyloricus was seen vaguely in five other goats.

The abomasum could be visualised equally well from either side and was approximately the same size on the left and right. It occupied more space cranially on the left but more space caudally on the right where it extended over a larger distance than on the left. From the linea alba, the visible 
101 cranial limit of the abomasum was $-0.3[2.34] \mathrm{cm}$ from the xyphoid and the caudal limit was 10.3

102 [3.08] cm caudal to the xyphoid. The visible length of the abomasum ranged from $7.0 \mathrm{~cm}$ to $15.0 \mathrm{~cm}$

$103(10.7[1.96] \mathrm{cm})$. The maximum width of the abomasum was 30.2 [7.43] $\mathrm{cm}$ and it occupied equal

104 space on the left $(15.1[3.72] \mathrm{cm})$ and right $(15.2[3.71] \mathrm{cm})$ sides of the linea alba. The height of the 105 abomasum was $6.7[1.79] \mathrm{cm}(3.3-10.6 \mathrm{~cm})$.

The reticulum was seen cranial to the abomasum when viewed from the linea alba in all the

107 goats, and the ventral sac of the rumen was observed caudal to the abomasum in all the goats. From

108 the right side, loops of small intestine were seen caudal to the abomasum in all but one goat. In 25

109 goats, the liver was seen on the right side and was lateral or dorsal to the abomasum. The gallbladder

110 was situated immediately dorsal to the abomasum in six goats, and the omasum was observed dorsal to

111 the abomasum in 21 goats.

Haemonchus contortus was found in the abomasum of nine goats. The abomasal mucosa

113 appeared macroscopically normal. There were no other abnormal findings.

The ultrasonographic appearance of the abomasum allowed it to be easily differentiated from adjacent organs. Its contents were hypoechogenic with hyperechogenic stippling, similar to that seen in

117 cattle (Braun et al., 1997a). However, there were distinct differences in the degree of homogeneity or 118 echogenicity of the abomasal contents among the goats. The abomasal folds were best seen with 119 homogeneous anechogenic or hypoechogenic abomasal contents and when the abomasum moved 120 cranially during a reticular contraction. It was very difficult to observe the pylorus because of the small 121 intestines, which were normally located in the caudal abomasal region. The pylorus was seen clearly in 122 only one goat. Similar findings were reported in cattle, in which the pylorus could be seen in only one 123 of 50 cows (Wild, 1995; Braun et al., 1997). The abomasal wall could not be easily differentiated from 124 the contents and abdominal wall and thus its thickness was not measured in any of the goats. The 
abomasal wall in cows was described as a thin echogenic line (Wild, 1995; Braun et al., 1997a). In

126

127

128

130

131

132

133

134

135

136

137

138

139

\section{Conclusions}

142

\section{Conclusions}

contrast to cattle, the caprine abomasum could be seen equally well and yielded similar measurements on both sides. The visible length of the abomasum in the region of the linea alba was 7.0 to $15.0 \mathrm{~cm}$.

The visible length in cattle ranged from 7.4 to $42.9 \mathrm{~cm}$ (Braun et al., 1997a). When determining the size of the abomasum in the region of the linea alba, one must remember that the abomasum is located between the reticulum and rumen and therefore, the measured length does not reflect the actual length.

This also applies for the height of the abomasum. It is often difficult to measure the height of the abomasum in the region of the linea alba because the depth of the organ is beyond the capacity of the transducer, or gas within the organ prevents adequate visualisation of the organ. Therefore, the measurements are highly dependent on the visibility of the abomasum and the nature of its contents. The findings of this study show that ultrasonography is very useful for the diagnosis of abomasal disorders in goats such as left displacement, enlargement caused by pyloric stenosis or retrograde dilation in animals with ileus. It is plausible that thickening of the abomasal wall caused by lymphosarcoma can also be diagnosed via ultrasonography. However, based on findings in cattle, it is unlikely that abomasal ulcers can be detected on ultrasonograms.

The results serve as reference values for ultrasonographic evaluation of the abomasum in goats. Ultrasonography is an important tool for non-invasive diagnosis of abomasal disorders in goats because conventional methods for examining this organ are limited. Ultrasonography provides information about the location, size and contents of the caprine abomasum. Knowledge of the normal ultrasonographic features of the abomasum is required for interpretation of lesions. 
150 organisations that could inappropriately influence or bias the content of the paper.

\section{References}

Bath, G. F., 1978. Abomasal phytobezoariasis of goats and sheep. Journal of the South African Veterinary Association 49, 133.

Bath, G. F., Bergh, T., 1979. A specific form of abomasal phytobezoar in goats and sheep. Journal of the South African Veterinary Association 50, 69-72.

Becker-Birck, M., 2009. Computertomographische Untersuchung des Thorax bei 30 Ziegen. DrMedVet Thesis, Vetsuisse Faculty, University of Zurich.

Braun, U., Wild, K., Guscetti, F., 1997a. Ultrasonographic examination of the abomasum of 50 cows. Veterinary Record 140, 93-98.

Braun, U., Pusterla, N., Schönmann, M., 1997b. Ultrasonographic findings in cows with left displacement of the abomasum. Veterinary Record 141, 331-335.

Braun, U., 2003. Ultrasonography in gastrointestinal disease in cattle. Veterinary Journal 166, 112124.

Braun, U., Feller, B., 2008. Ultrasonographic findings in cows with right displacement of the abomasum and abomasal volvulus. Veterinary Record 162, 311-315.

167 Cegarra, I. J., Lewis, R. E., 1977. Contrast study of the gastrointestinal tract in the goat (Capra hircus). American Journal of Veterinary Research 38, 1121-1128.

Edwards, G. T., Nevel, A., 2008. Abomasal emptying defect in two British Toggenburg goats. Veterinary Record 162, 418-419. Thesis, Vetsuisse Faculty, University of Zurich. 
Jacquat, D., 2010. Sonographische Untersuchung von Haube, Pansen, Psalter und Labmagen bei 30 Ziegen. DrMedVet Thesis, Vetsuisse Faculty, University of Zurich.

Linklater, K. A., Smith, M. C., 1993. Conditions affecting the abomasum. In: Diseases and Disorders of the Sheep and Goat. Mosby-Wolfe, London, pp. 60-62.

Matthews, J., 2009a. Diarrhoea. In: Diseases of the Goat. Wiley-Blackwell Science, Oxford, pp. 236267.

Matthews, J., 2009b. Abdominal distension. In: Diseases of the Goat. Wiley-Blackwell Science, Oxford, pp. 290-297.

Pérez, J., Garcia, P. M., Hernandez, S., Martinez-Moreno, A., Martin de las Mulas, J., Camara, S., 2001. Pathological and immunohistochemical study of the abomasum and abomasal lymph nodes in goats experimentally infected with Haemonchus contortus. Veterinary Research 32, 463-473.

Purohit, R. K., Chouhan, D. S., Purohit, N. R., Sharma, S. S., 1986. Abomasal impaction in goat with metallic particles. Indian Journal of Veterinary Surgery 7, 63-64.

Schummer, A., Wilkens, H., 1987. Rumpfdarm der Wiederkäuer. In: Nickel, R., Schummer, A., Seiferle, E. (Eds.), Lehrbuch der Anatomie der Haustiere. Volume II. Paul Parey Verlag, Berlin, Hamburg, pp. 158-194.

Sherman, D. M., 1981. Duodenal obstruction by a phytobezoar in a goat. Journal of the American Veterinary Medical Association 178, 139-140.

Smith, M. C., Sherman, D. M., 2009. Digestive system. In: Goat Medicine. Wyley-Blackwell, Ames, pp. 377-500.

Steininger, K., 2009. Ultraschalluntersuchung von Leber, Milz, Dünndarm, Dickdarm und Harnapparat bei 30 Ziegen. DrMedVet Thesis, Vetsuisse Faculty, University of Zurich.

West, G. A., Dale, T., Mayhew, R. F., 1983. Left displacement of the abomasum in a goat. Veterinary Medicine / Small Animal Clinician 78, 1919-1921. 
197 Wild, K., 1995. Sonographische Untersuchungen am Labmagen des Rindes. DrMedVet Thesis, Vetsuisse Faculty, University of Zurich.

199 Wittek, T., Constable, P. D., Marshall, T. S., Crochik, S. S., 2005. Ultrasonographic measurement of 200 abomasal volume, location, and emptying rate in calves. American Journal of Veterinary Research 201 $66,537-544$.

202 


\section{Legends to figures}

204 Figure 1: Schematic representation of the location, length and width of the abomasum in Saanen goats. A Xyphoid, B Abomasum, 1 Distance between the cranial abomasal limit and the end of the xyphoid, 2 Distance between the caudal abomasal limit and the end of the xyphoid, 3 Visible length of the abomasum, 4 Visible width of the abomasum.

Figure 2: Schematic representation of determination of the height and length of the abomasum in Saanen goats. A Reticulum, B Anterior dorsal blind sac of the rumen, C Dorsal sac of the rumen, D Ventral sac of the rumen, E Abomasum, 1 Visible height of the abomasum, 2 Visible length of the abomasum.

Figure 3: Ultrasonogram of the abomasum of a five-year-old Saanen goat, viewed from the left ventral paramedian region using a 5.0 MHz convex transducer. The abomasum is seen caudal to the reticulum and appears as a heterogeneous, moderately echogenic structure with multifocal echogenic foci. 1 Abdominal wall, 2 Abomasum, 3 Reticulum, Cr Cranial, Cd Caudal.

Figure 4 : Ultrasonogram showing an abomasal fold in a 3.5-year-old Saanen goat, viewed from the

Figure 5 : Ultrasonogram showing the pylorus in a four-year-old Saanen goat, viewed from the 10th intercostal space on the right using a 5.0 MHz linear transducer. The pylorus has a heterogenous echogenic appearance and is round to oval in cross section. 1 Lateral abdominal wall, 2 Pylorus, 3 Small intestines, Ds Dorsal, Vt Ventral. 
$225 \quad$ Figure 1

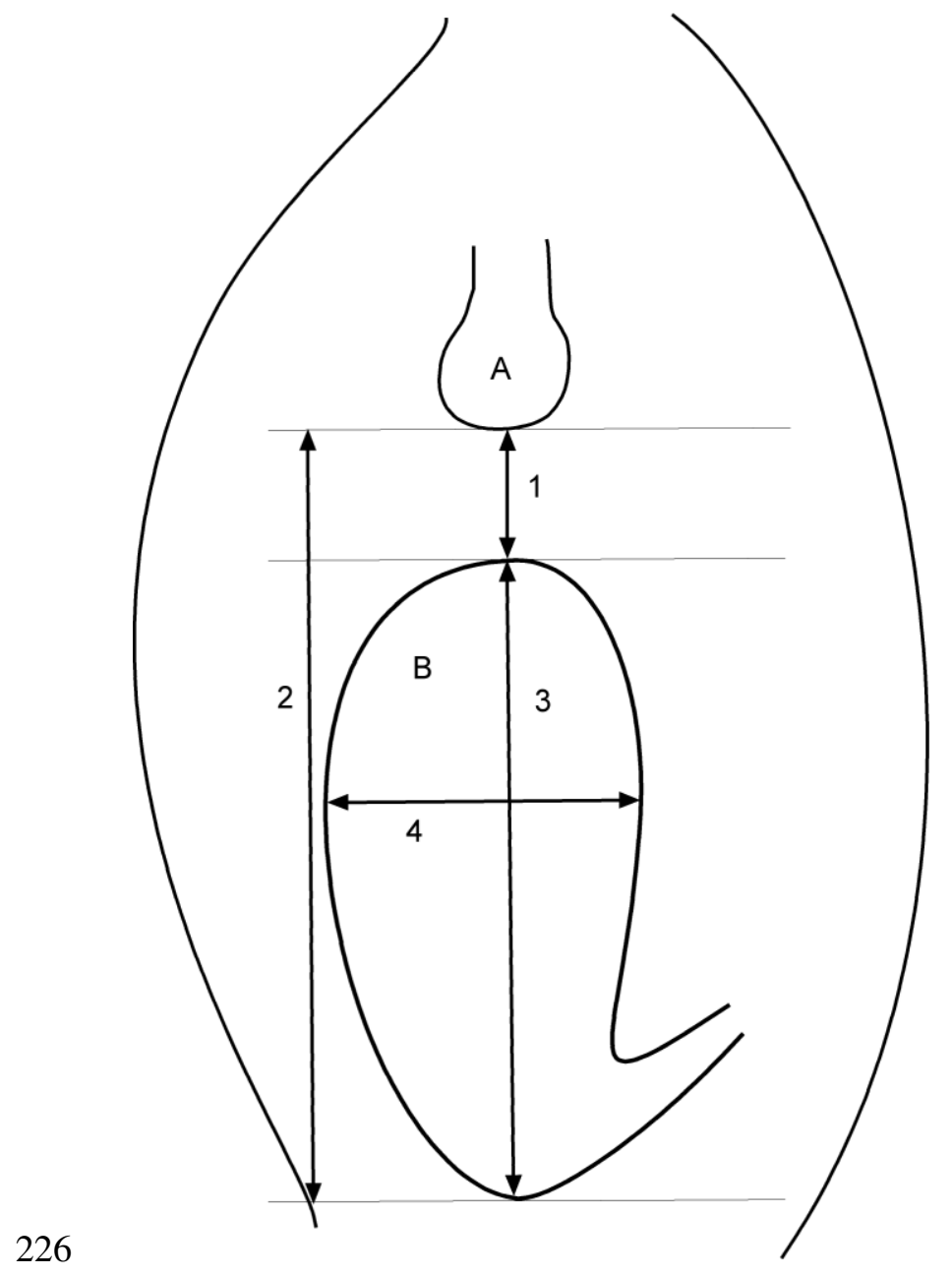

227

$228 \quad$ Figure 2

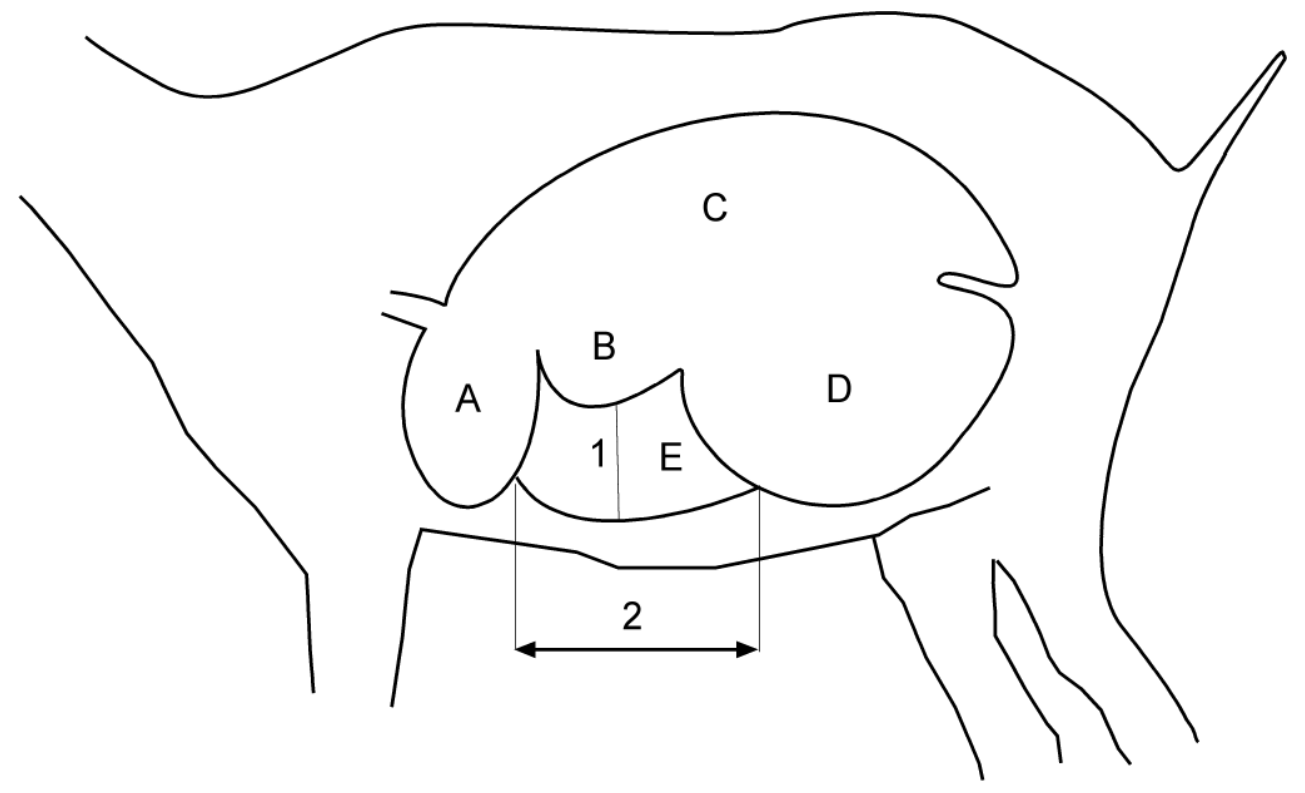


$230 \quad$ Figure 3

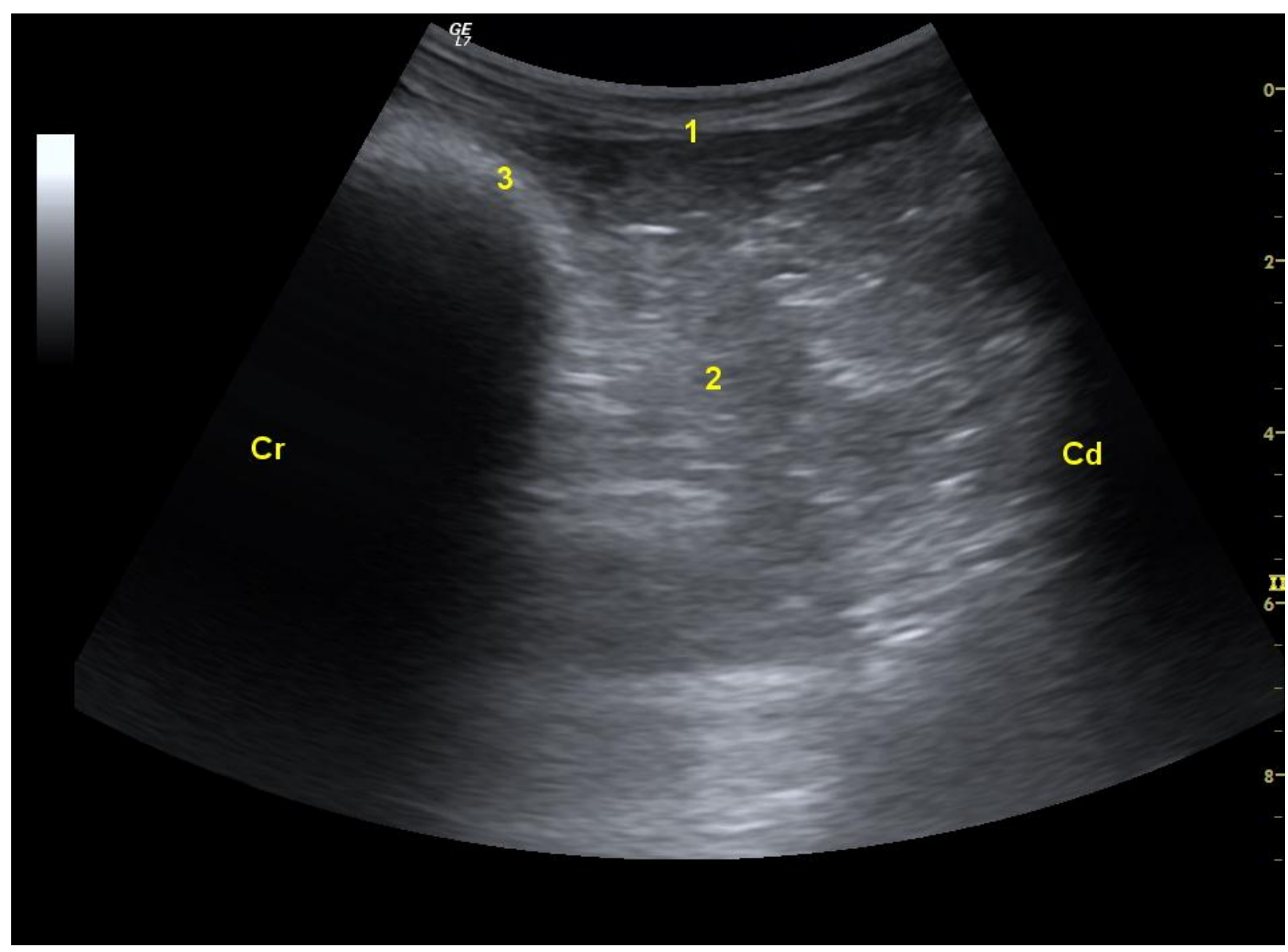

232

233 
$234 \quad$ Figure 4

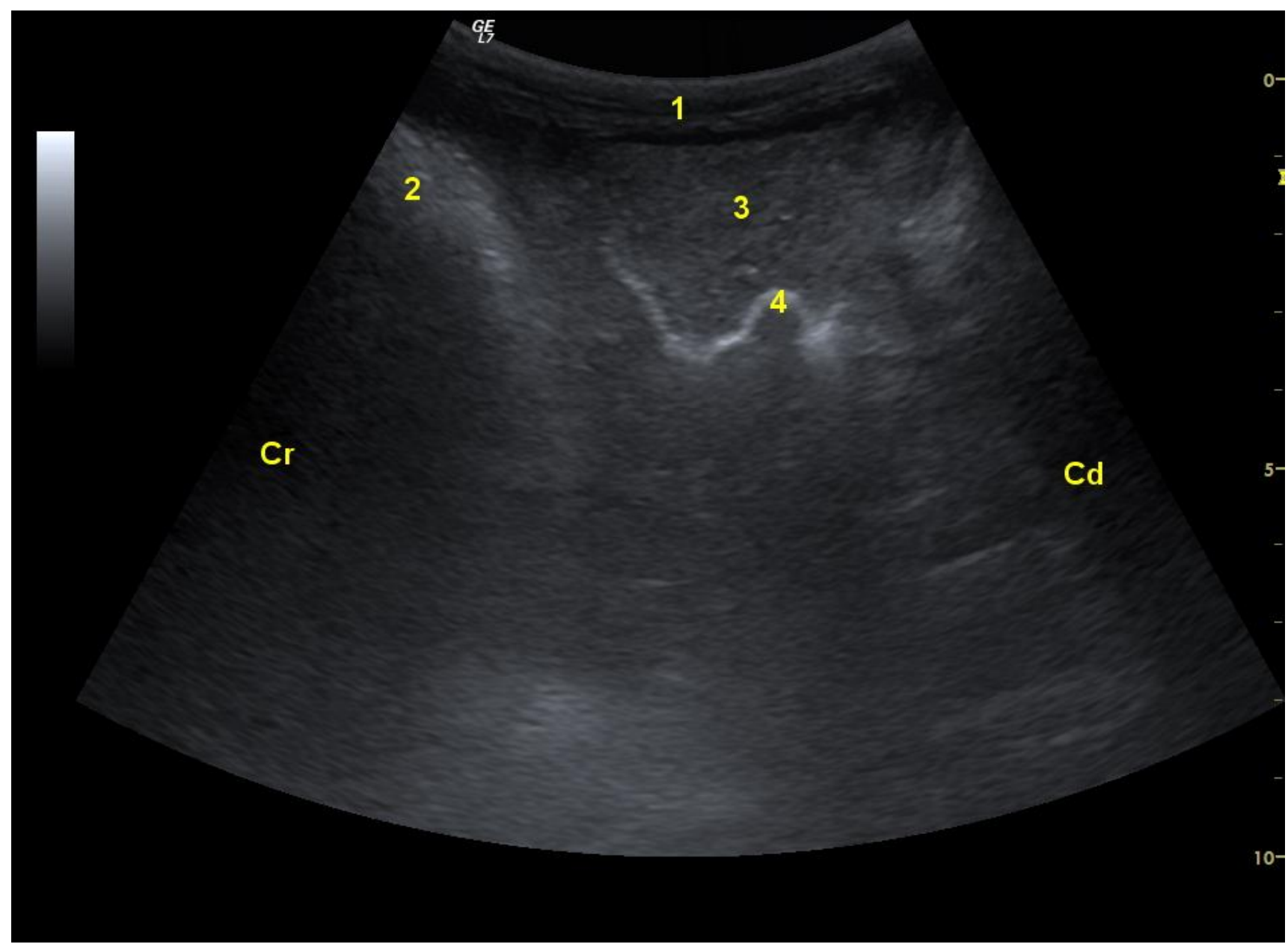


$238 \quad$ Figure 5

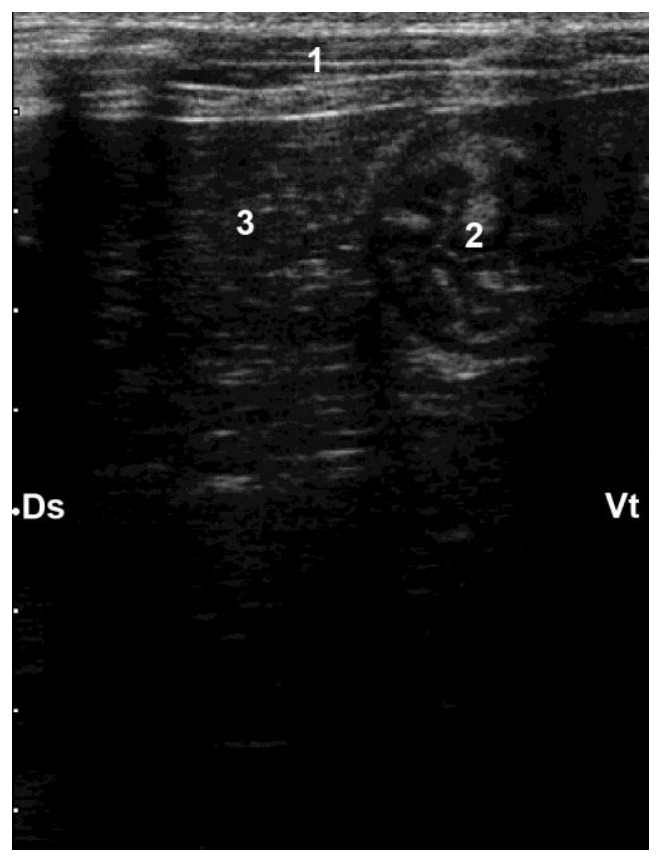

239 